\title{
Role of Free Fatty Acids and Insulin in Determining Free Fatty Acid and Lipid Oxidation in Man
}

\author{
Leif C. Groop, Riccardo C. Bonadonna, Myron Shank, Alexander S. Petrides, and Ralph A. Defronzo \\ Fourth Department of Medicine, Helsinki University Hospital, Helsinki, Finland; Division of Endocrinology/Diabetes, \\ Department of Medicine, Yale University School of Medicine, New Haven, Connecticut 06504; \\ and Diabetes Division, Department of Medicine, University of Texas Health Science Center, and \\ Veterans Administration Hospital, San Antonio, Texas 78284-7886
}

\begin{abstract}
Plasma FFA oxidation (measured by infusion of ${ }^{14} \mathrm{C}$-palmitate) and net lipid oxidation (indirect calorimetry) are both inhibited by insulin. The present study was designed to examine whether these insulin-mediated effects on lipid metabolism resulted from a decline in circulating FFA levels or from a direct action of the hormone on FFA/lipid oxidation. Nine subjects participated in two euglycemic insulin clamps, performed with and without heparin. During each insulin clamp study insulin was infused at two rates, 4 and $20 \mathrm{mU} / \mathrm{m}^{2} \cdot \mathrm{min}$ for $120 \mathrm{~min}$. The studies were performed with indirect calorimetry and $3-{ }^{3} \mathrm{H}$-glucose and ${ }^{14} \mathrm{C}$-palmitate infusion. During the control study plasma FFA fell from $610 \pm 46$ to $232 \pm 42$ to $154 \pm 27 \mu \mathrm{mol} /$ liter, respectively. When heparin was infused basal plasma FFA concentration remained constant. During the control study, FFA/lipid oxidation rates decreased in parallel with the fall in the plasma FFA concentration. During the insulin/heparin study, plasma ${ }^{14} \mathrm{C}$-FFA oxidation remained unchanged while net lipid oxidation decreased. In conclusion, when the plasma FFA concentration is maintained unchanged by heparin infusion, insulin has no direct effect on FFA turnover and disposal. These results thus suggest that plasma FFA oxidation is primarily determined by the plasma FFA concentration, while net lipid oxidation is regulated by both the plasma FFA and the insulin level. (J. Clin. Invest. 1991. 87:83-89.) Key words: free fatty acid • insulin • lipid oxidation • glucose disposal
\end{abstract}

\section{Introduction}

In normal and diabetic subjects insulin is known to suppress lipid oxidation as measured by indirect calorimetry $(1,2)$. However, indirect calorimetry measures net lipid oxidation which includes both oxidation of plasma FFA and oxidation of intracellular lipids (3-5). The oxidation of plasma FFA, which can be measured with ${ }^{14} \mathrm{C}$-labeled palmitate, is inhibited by small increments in the plasma insulin concentration $(6,7)$. The decrease in FFA oxidation could result from decreased substrate level, secondary to an inhibition of lipolysis, or could result from a direct effect of insulin on FFA oxidation. Because both

Address correspondence to Leif C. Groop, M.D., Fourth Department of Medicine, Helsinki University Hospital, Unioninkatu 38, SF-00170 Helsinki, Finland.

Received for publication 17 November 1989 and in revised form 19 July 1990.

J. Clin. Invest.

(C) The American Society for Clinical Investigation, Inc.

0021-9738/91/01/0083/07 \$2.00

Volume 87, January 1991, 83-89 lipolysis and FFA oxidation may be regulated in concert by insulin, it is difficult to draw conclusions about the effect(s) of insulin on lipid/FFA oxidation when the plasma FFA concentration is changing. To circumvent this problem, we have examined the effect of insulin on lipid/FFA oxidation under conditions where the plasma FFA concentration has been kept constant at the basal level by an infusion of heparin. A second aim of the study was to examine the effect of different FFA concentrations on the suppression of hepatic glucose production and stimulation of glucose disposal by insulin. Our data provide evidence that insulin has no direct effect on plasma FFA oxidation but markedly inhibits the oxidation of intracellular lipids.

\section{Methods}

Subjects. Nine healthy young subjects (seven males, two females) with a mean ( \pm SEM) age of $22 \pm 1$ yr and ideal body weight of $102 \pm 2 \%$ were studied. All subjects had a normal oral glucose tolerance test according to the revised criteria of the National Diabetes Data Group. The fasting plasma glucose was $86 \pm 1 \mathrm{mg} / \mathrm{dl}$ and fasting plasma insulin concentration was $7 \pm 1 \mu \mathrm{U} / \mathrm{ml}$. None of the subjects had any clinical or laboratory evidence of hepatic, renal, or other endocrine disease. All subjects were consuming a weight-maintaining diet containing at least $200 \mathrm{~g}$ of carbohydrate per day for $2 \mathrm{wk}$ before study. Before participating in the experimental protocol, the purpose, nature, and potential risks of the study were explained to all subjects and informed written voluntary consent was obtained. The study protocol was approved by the Human Investigation Committee of the Yale University School of Medicine.

Experimental protocol. All subjects participated in two experiments which were carried out in random order with a 2-wk interval. During the first experiment a two-step euglycemic insulin clamp $(+4$ and +20 $\mathrm{mU} / \mathrm{m}^{2} \cdot \mathrm{min}$ ) was performed (8) with each insulin infusion lasting 120 $\min$. The second experiment was similar to the first with one exception; at the beginning of the $4 \mathrm{mU} / \mathrm{m}^{2} \cdot \mathrm{min}$ insulin infusion subjects received a primed $(200 \mathrm{U})$-continuous $(25 \mathrm{U} / \mathrm{min})$ infusion of heparin to stimulate lipoprotein lipase. At the start of the second insulin infusion step $\left(20 \mathrm{mU} / \mathrm{m}^{2} \cdot \mathrm{min}\right)$ subjects received a second heparin bolus $(200$ $\mathrm{U})$ followed by a continuous infusion at $35 \mathrm{U} / \mathrm{min}$. All studies were performed with indirect calorimetry and infusion of $3-{ }^{3} \mathrm{H}$-glucose and ${ }^{14} \mathrm{C}$-palmitate to quantitate respiratory gas exchange, hepatic glucose production, and FFA oxidation, respectively. The low insulin infusion protocol $\left(4 \mathrm{mU} / \mathrm{m}^{2} \cdot \mathrm{min}\right)$ was designed to examine whether differences in the plasma FFA concentration would influence the effect of insulin on the liver. The $20 \mathrm{mU} / \mathrm{m}^{2} \cdot \mathrm{min}$ insulin infusion protocol, on the other hand, allowed us to examine whether differences in the plasma FFA concentration would affect the capacity of insulin to stimulate peripheral glucose uptake.

Euglycemic insulin clamp. The subjects were admitted to the Clinical Research Center on the morning of study. All studies were initiated at 0800 after a 12-h overnight fast. Before the study Teflon catheters were inserted into an antecubital vein for infusion of test substances and retrogradely into a wrist vein for withdrawal of blood samples. The hand was then inserted into a heated box $\left(70^{\circ} \mathrm{C}\right)$ to achieve arterialization of venous blood. After obtaining four basal samples for insulin, glucose, and FFA a primed-continuous infusion $\left(4 \mathrm{mU} / \mathrm{m}^{2} \cdot \mathrm{min}\right)$ of 
crystalline porcine insulin (Lilly, Indianapolis, IN) was started to acutely raise and maintain the plasma insulin concentration at the desired level for $120 \mathrm{~min}$. The plasma glucose concentration was determined every $5 \mathrm{~min}$ and a variable infusion of $20 \%$ glucose was adjusted to maintain the plasma glucose concentration constant at the basal level (8). At $120 \mathrm{~min}$ the insulin space was reprimed and the second insulin infusion $\left(20 \mathrm{mU} / \mathrm{m}^{2} \cdot \mathrm{min}\right)$ started and maintained for another $120 \mathrm{~min}$. Blood samples for plasma insulin and FFA concentrations were drawn at 15 -min intervals.

Tritiated glucose. At $150 \mathrm{~min}$ before the start of insulin, a primed $(25 \mu \mathrm{Ci})$-continuous $(0.25 \mu \mathrm{Ci} / \mathrm{min})$ infusion of $3{ }^{3} \mathrm{H}$-glucose (New England Nuclear, Boston, MA) was begun. Baseline samples for determination of $3-{ }^{3} \mathrm{H}$-glucose specific activity were drawn at 5 -min intervals during the last $30 \mathrm{~min}$ of the equilibration period. During the insulin clamp, $3-{ }^{3} \mathrm{H}$-glucose samples were drawn at 15 -min intervals until the last $20 \mathrm{~min}$, during which time they were obtained at 5-min intervals. All subjects achieved a steady-state level of plasma tritiated glucose specific activity at the end of the basal equilibration period.

FFA turnover. ${ }^{14} \mathrm{C}$-Palmitate (New England Nuclear) was utilized to quantitate plasma FFA turnover $(6,9)$. A priming dose of $2.5 \mu \mathrm{Ci}$ ${ }^{14} \mathrm{C}$-palmitate was injected $150 \mathrm{~min}$ before the first insulin infusion and this was followed by a constant infusion at $0.1 \mu \mathrm{Ci} / \mathrm{min}$ throughout the study. Simultaneously, a bolus injection of $3.5 \mu \mathrm{Ci}$ of $\left[1-{ }^{14} \mathrm{C}\right]-\mathrm{NaHCO}_{3}$ (New England Nuclear) was given to prime the bicarbonate pool. Baseline samples for determination of ${ }^{14} \mathrm{C}$-FFA plasma specific activity were drawn at 5-min intervals during the last $30 \mathrm{~min}$ of the equilibration period. During the insulin clamp ${ }^{14} \mathrm{C}$-FFA samples were drawn at $30,60,75,90,100,110,120,150,180,195,210,220,230$, and $240 \mathrm{~min}$.

FFA oxidation. The rate of FFA oxidation during the ${ }^{14} \mathrm{C}$-palmitate infusion was calculated from the specific activity of expired $\mathrm{CO}_{2}$ in air samples obtained at 5-min intervals during the last $30 \mathrm{~min}$ of the equilibration period and at $60,90,100,110,120,180,210,220,230$, and 240 min of the insulin clamp $(6,10)$. Each expired air sample was bubbled through a 3-ml sample of carbon dioxide trapping solution (1 M hyamine hydroxide:absolute ethanol:0.1\% phenolphtalein; 3:5:1). The capacity of the trapping solution to trap $1 \mathrm{mmol}$ of $\mathrm{CO}_{2}$ was checked with $1 \mathrm{~N} \mathrm{HCl}$. The ${ }^{14} \mathrm{C}$-radioactivity was subsequently determined on duplicates in a Packard Tricarb Scintillation counter (Packard Instrument Co. Inc., Downers Grove, IL) and the expired ${ }^{14} \mathrm{CO}_{2}$ specific activity calculated. Total ${ }^{14} \mathrm{CO}_{2}$ expired per minute was determined by multiplying the ${ }^{14} \mathrm{CO}_{2}$ specific activity by the total $\mathrm{CO}_{2}$ production rate determined by indirect calorimetry (see below).

Respiratory gas exchange measurements. All studies were performed with continuous indirect calorimetry to estimate net rates of carbohydrate and lipid oxidation (3). Starting $60 \mathrm{~min}$ before and continuing from 60 to $120 \mathrm{~min}$ and from 180 to $240 \mathrm{~min}$ of the insulin clamp, continuous gaseous exchange measurements were performed with a ventilated hood system (Vista, Vacumed, Ventura, CA). Ventilation was measured by means of a dry gas meter. A constant fraction of the air flowing out of the hood was automatically collected for analysis. Oxygen was measured by electrochemical analysis and $\mathrm{CO}_{2}$ content by an infrared analyzer using Applied Electrochemistry Instruments (Sunnyvale, CA). Protein oxidation was calculated from the urinary nitrogen excretion obtained before and during the insulin clamp (3).

\section{Analytical determinations}

Plasma glucose was determined in duplicate by the glucose oxidase method on a glucose analyzer II (Beckman Instruments, Inc., Fullerton, CA). Methods for determination of plasma tritiated glucose specific activity have been published previously (11). Blood for determination of insulin, FFA and ${ }^{14} \mathrm{C}$-FFA specific activity was sampled into prechilled tubes and immediately centrifuged. Plasma insulin was measured by specific radioimmunoassay (12), urinary nitrogen excretion by the method of Kjeldahl (13), and plasma FFA concentrations were measured by the microfluorometric method of Miles et al. (14). The method for determination of ${ }^{14} \mathrm{C}$-FFA specific activity in plasma has been described in detail previously (6).

\section{Calculations}

Hepatic glucose production (HGP). Basal HGP was calculated by dividing the $3-{ }^{3} \mathrm{H}$-glucose infusion rate by the steady-state plateau of plasma $3-{ }^{3} \mathrm{H}$-glucose specific activity achieved during the last $30 \mathrm{~min}$ of the basal tracer infusion period. After administration of insulin and glucose a non-steady state condition in glucose specific activity exists, and the rate of glucose appearance $\left(R_{\mathrm{a}}\right)$ was calculated by the model described by Radziuk (15). The infusion rate of cold glucose was integrated over 20-min intervals and subtracted from the total $R_{\mathrm{a}}$ calculated during the same 20 -min period to obtain the rate of HGP. Negative numbers for HGP were observed occassionally during the 20 $\mathrm{mU} / \mathrm{m}^{2} \cdot \min$ insulin clamp step. As recently demonstrated on theoretical as well as experimental grounds (16), such underestimation of glucose turnover by the tracer method is largely accounted for by a model error emerging at high rates of glucose metabolism. Because a simple and satisfactory correction for changes in the glucose system during the non-steady state is not yet available, we took the negative numbers to indicate complete suppression of HGP.

Glucose metabolism. During the insulin clamp the mean glucose infusion rate was determined during the last $60 \mathrm{~min}$ of each insulin clamp step. Total body glucose metabolism was calculated by adding the rate of residual endogenous glucose production during the last 60 min of each insulin clamp step to the mean glucose infusion rate during the same period. Nonoxidative glucose metabolism during the last 60 min of each insulin clamp step was calculated as the difference between total body glucose uptake and glucose oxidation as determined by indirect calorimetry.

Indirect calorimetry. Net glucose and lipid oxidation rates were estimated from indirect calorimetric measurements in the basal state and during the last $60 \mathrm{~min}$ of each insulin infusion step. The constants to calculate glucose, lipid, and protein oxidation from gas exchange data and nonprotein urinary nitrogen excretion are those in reference 3 . To allow direct comparison with ${ }^{14} \mathrm{C}$-FFA oxidation, net lipid oxidation (in milligrams) has been converted to moles by dividing by the molecular weight of palmitate (mol wt 256). At a non-protein respiratory quotient $>1.0$, the equation for the calculation of substrate oxidation remains valid (3); the resulting negative value for lipid oxidation is in fact equivalent to net fat synthesis (3).

Plasma FFA turnover. Palmitic acid accounts for $\sim 30 \%$ of the total FFA pool independently of the plasma FFA concentration (17). Because the fractional turnover of palmitate is very similar to that of total FFA, labeled palmitate can be used to trace total FFA (17). The plasma FFA turnover rate was calculated as palmitate infusion rate divided by the steady-state plasma FFA specific activity and is expressed as $\mu \mathrm{mol} / \mathrm{kg} \cdot \mathrm{min}$. Using this approach the specific activities of both plasma ${ }^{14} \mathrm{C}$-FFA and of ${ }^{14} \mathrm{CO}_{2}$ in expired air are in steady state during the last $30 \mathrm{~min}$ of the equilibration period and a new steady state is achieved during the last $60 \mathrm{~min}$ of each insulin clamp step (Fig. 1) (6). We have therefore assumed steady-state conditions to calculate the rates of FFA turnover and FFA oxidation.

Metabolic clearance rate of FFA $\left(M C R_{F F A}\right)$. The metabolic clearance rate of plasma FFA $(\mathrm{ml} / \mathrm{kg} \cdot \mathrm{min})$ was calculated by dividing the basal or steady-state plasma FFA turnover rate by the plasma FFA concentration during the same period.

FFA oxidation. The rate of oxidation of plasma FFA in the basal state and during the euglycemic insulin clamp was calculated from the ${ }^{14} \mathrm{C}$ radioactivity in expired $\mathrm{CO}_{2}$ divided by the product of the plasma FFA specific activity and a factor $k$, which takes into account the incomplete recovery of labeled ${ }^{14} \mathrm{CO}_{2}$ from the bicarbonate pool $(6,10)$.

FFA oxidation rate $(\mu \mathrm{mol} / \mathrm{kg} \cdot \mathrm{min})=\left(\mathrm{S} . \mathrm{A} . \mathrm{CO}_{2}\right) \times \mathrm{VCO}_{2} / k$ $\times\left(\right.$ S.A. $\cdot{ }^{14} \mathrm{C}$-FFA), where S.A. ${ }^{14} \mathrm{CO}_{2}=$ specific activity of $\mathrm{CO}_{2}$ in expired air; $\mathrm{VCO}_{2}=$ total $\mathrm{CO}_{2}$ production (to change $\mathrm{ml} / \mathrm{min}$ to $\mu \mathrm{mol} / \mathrm{min}$, divide by 22.4 ); S.A. ${ }^{14} \mathrm{C}-\mathrm{FFA}=$ specific activity of ${ }^{14} \mathrm{C}$-FFA in plasma, and $k=0.81$.

Nonoxidative FFA disposal. Nonoxidative FFA disposal, a measure of FFA reesterification, was calculated as the difference between total FFA turnover and FFA oxidation $(6,18)$. 
FFA SPECIFIC ACTIVITY
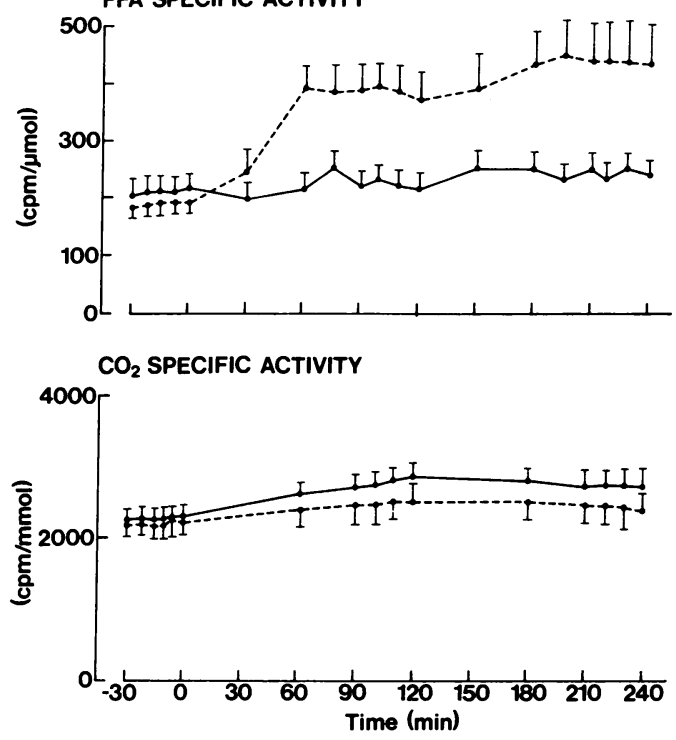

Figure 1. The specific activity of FFA in plasma (top) and of $\mathrm{CO}_{2}$ in expired air (bottom) in the basal state and during a two-step euglycemic insulin clamp (insulin infusion rates of 4 and 20 $\mathrm{mU} / \mathrm{m}^{2} \cdot \mathrm{min}$ ) performed with saline (broken line) and with heparin (solid line). Values represent the mean $\pm \operatorname{SEM}(n=9)$.

Intracellular (unlabeled) FFA oxidation was calculated as the difference between net lipid oxidation (indirect calorimetry) and plasma FFA oxidation. It should be noted that this represents a minimal estimate of intracellular FFA oxidation because net lipid oxidation, as determined by indirect calorimetry, equals the difference between lipid oxidation and lipid synthesis.

\section{Statistical analysis}

Data are presented as mean \pm SEM. Significance of differences between the two experiments was calculated with analysis of variance. Pearson's correlation coefficients were calculated by standard formulae.

\section{Results}

Plasma glucose, insulin, and FFA concentrations. The fasting plasma glucose concentration during the control and heparin experiments was $86 \pm 2$ and $85 \pm 2 \mathrm{mg} / \mathrm{dl}$, respectively. The mean plasma glucose during the 4 and $20 \mathrm{mU} / \mathrm{m}^{2} \cdot \min$ insulin clamp steps of both studies was similar and averaged $84 \pm 2$ $\mathrm{mg} / \mathrm{dl}$. The coefficients of variation of the plasma glucose were $3.9 \pm 0.5 \%$ and $3.7 \pm 0.5 \%$, respectively, during control and heparin experiments. The fasting plasma insulin concentration during the control study was $6 \pm 1 \mu \mathrm{U} / \mathrm{ml}$ and rose to $11 \pm 1$ and $36 \pm 2 \mu \mathrm{U} / \mathrm{ml}$, respectively, during the 4 and $20 \mathrm{mU} / \mathrm{m}^{2} \cdot \min$ insulin clamp steps (Fig. 2). The basal plasma insulin concentration in the heparin experiment was $7 \pm 1 \mu \mathrm{U} / \mathrm{ml}$ and rose to $11 \pm 1$ and $36 \pm 2 \mu \mathrm{U} / \mathrm{ml}$, respectively. The coefficients of variation in plasma insulin during the control and the heparin experiment were $7.4 \pm 0.8 \%$ and $7.5 \pm 0.9 \%$, respectively.

The basal plasma FFA concentration during the control study was $610 \pm 46 \mu \mathrm{mol} /$ liter and fell to $232 \pm 42$ and $154 \pm 27$ $\mu \mathrm{U} /$ liter, respectively, during the 4 and $20 \mathrm{mU} / \mathrm{m}^{2} \cdot \min$ insulin clamp steps (Fig. 2). The basal plasma FFA concentration during the heparin study, $646 \pm 77 \mu \mathrm{mol} / \mathrm{liter}$ was maintained at $725 \pm 129$ and $524 \pm 100 \mu \mathrm{mol} /$ liter, respectively, during the 4 and $20 \mathrm{mU} / \mathrm{m}^{2} \cdot \mathrm{min}$ insulin clamp steps.

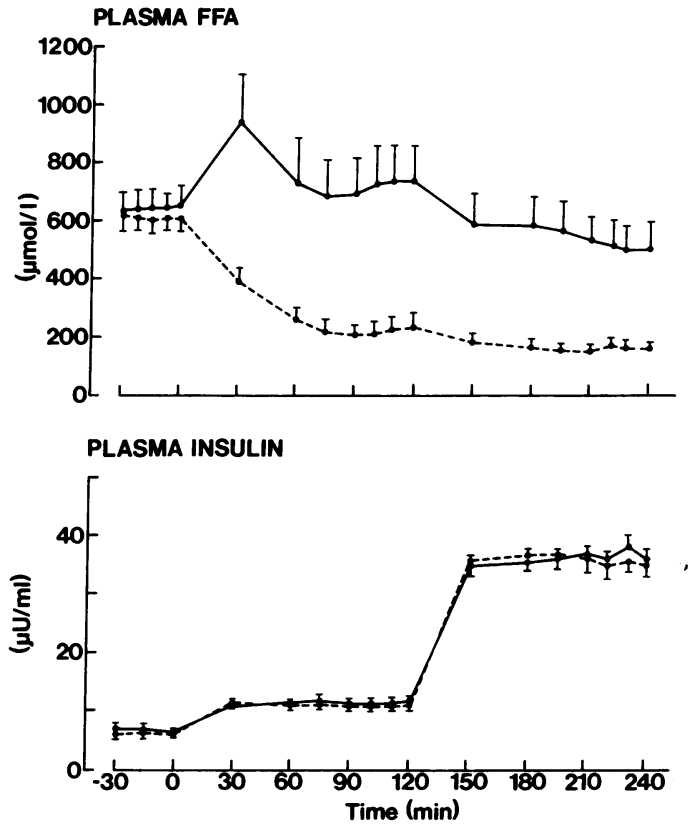

Figure 2. The plasma FFA (top) and insulin (bottom) concentrations in the basal state and during a two-step euglycemic insulin clamp (insulin infusion rates of 4 and $20 \mathrm{mU} / \mathrm{m}^{2} \cdot \mathrm{min}$ ) performed with saline (broken line) and with heparin (solid line). Values represent the mean $\pm \operatorname{SEM}(n=9)$.

\section{FFA metabolism}

FFA turnover rate. The basal rate of FFA turnover was similar during the control and the heparin experiments $(5.97 \pm 0.67 \mathrm{vs}$. $6.46 \pm 0.6 \mu \mathrm{mol} / \mathrm{kg} \cdot \mathrm{min}$ ) (Fig. 3). During the control experiment the plasma FFA turnover rate decreased by $50 \%$ during the low-dose insulin infusion (to $2.99 \pm 0.39 \mu \mathrm{mol} / \mathrm{kg} \cdot \mathrm{min}$ ) and
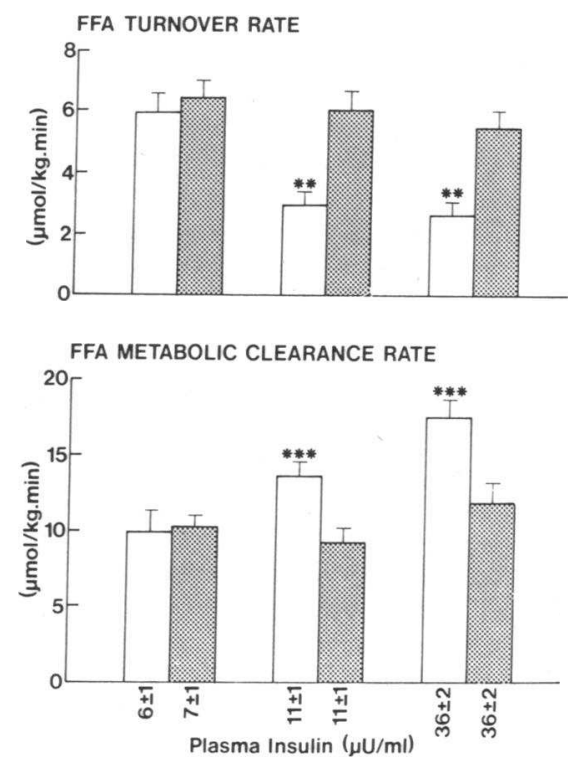

Figure 3. The plasma FFA turnover rate (top) and metabolic clearance rate of FFA (bottom) in the basal state and during a two-step euglycemic insulin clamp (insulin infusion rates of 4 and 20 $\mathrm{mU} / \mathrm{m}^{2} \cdot \mathrm{min}$ ) performed with saline (open bars) and with heparin (shaded bars). Values represent mean $\pm \operatorname{SEM}(n=9)$. ${ }^{* * *} P<0.001$, ${ }^{* *} P<0.01$, significance of difference from the heparin experiment. 
no significant further reduction was observed during the 20 $\mathrm{mU} / \mathrm{m}^{2} \cdot \mathrm{min}$ insulin infusion step $(2.61 \pm 0.4)$. During the insulin clamp study performed with heparin, the plasma FFA turnover rate was not significantly different from baseline during the 4 and $20 \mathrm{mU} / \mathrm{m}^{2} \cdot \mathrm{min}$ insulin infusion steps $(6.01 \pm 0.77$ and $5.42 \pm 0.69 \mu \mathrm{mol} / \mathrm{kg} \cdot \mathrm{min}$, respectively). However, the plasma FFA turnover rate during the insulin clamp performed with heparin was significantly greater than that during the control study (no heparin) $(P<0.01)$.

Metabolic clearance rate of FFA $\left(M C R_{F F A}\right)$. In the control experiment the basal $\mathrm{MCR}_{\mathrm{FFA}}$ rose from $9.6 \pm 0.8 \mathrm{ml} / \mathrm{kg} \cdot \mathrm{min}$ to $13.7 \pm 1.0$ and $17.6 \pm 1.2 \mathrm{ml} / \mathrm{kg} \cdot \mathrm{min}$, respectively, during the 4 and $20 \mathrm{mU} / \mathrm{m}^{2} \cdot \mathrm{min}$ insulin clamp steps (Fig. 3). In contrast, during heparin infusion the basal MCR $_{\text {FFA }}(10.3 \pm 0.7 \mathrm{ml} /$ $\mathrm{kg} \cdot \mathrm{min}$ ) did not change significantly during either the 4 $(9.3 \pm 1.0 \mathrm{ml} / \mathrm{kg} \cdot \mathrm{min})$ or $20 \mathrm{mU} / \mathrm{m}^{2} \cdot \min (11.6 \pm 1.2 \mathrm{ml} /$ $\mathrm{kg} \cdot \mathrm{min}$ ) insulin clamp steps.

Net lipid oxidation. The basal rate of total net lipid oxidation was $3.36 \pm 0.21$ and $3.12 \pm 0.37 \mu \mathrm{mol} / \mathrm{kg} \cdot \mathrm{min}$, respectively, during control and heparin experiments (Fig. 4). During lowdose insulin infusion, lipid oxidation did not change signifi-
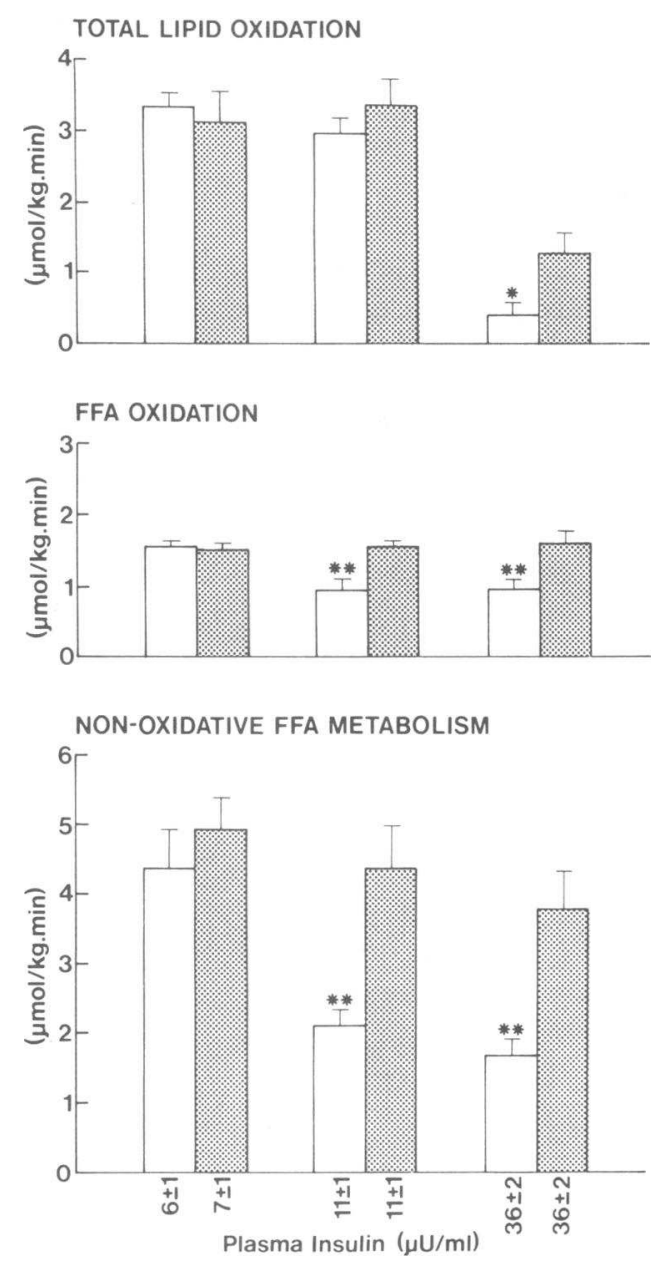

Figure 4. The rates of net lipid oxidation, plasma FFA oxidation and nonoxidative FFA metabolism in the basal state and during a twostep euglycemic insulin clamp (insulin infusion rates of 4 and 20 $\mathrm{mU} / \mathrm{m}^{2} \cdot \mathrm{min}$ ) performed with saline (open bars) and with heparin (shaded bars). Values represent mean $\pm \operatorname{SEM}(n=9) .{ }^{*} P<0.05,{ }^{* *} P$ $<0.01$, significance of difference from the heparin experiment. cantly in either control $(2.98 \pm 0.21 \mu \mathrm{mol} / \mathrm{kg} \cdot \mathrm{min})$ or heparin $(3.37 \pm 0.41)$ experiments. During the $20 \mathrm{mU} / \mathrm{m}^{2} \cdot \min$ insulin infusion, net lipid oxidation fell in both the control and heparin studies $(P<0.01)$; however, the reduction was significantly greater in the control experiment $(0.39 \pm 0.16$ vs. $1.24 \pm 0.32$ $\mu \mathrm{mol} / \mathrm{kg} \cdot \min ; P<0.01)$.

FFA oxidation. The basal rate of plasma FFA oxidation, which accounted for $\sim 50 \%$ of basal net lipid oxidation, was similar in control $(1.57 \pm 0.15 \mu \mathrm{mol} / \mathrm{kg} \cdot \mathrm{min})$ and heparin $(1.50 \pm 0.14 \mu \mathrm{mol} / \mathrm{kg} \cdot \mathrm{min})$ studies (Fig. 4). In the control experiment, plasma FFA oxidation was reduced by $45 \%$ at the low-dose insulin infusion $(0.86 \pm 0.15 \mu \mathrm{mol} / \mathrm{kg} \cdot \mathrm{min})$ and did not change further during the $20 \mathrm{mU} / \mathrm{m}^{2} \cdot \mathrm{min}$ insulin infusion $(0.92 \pm 0.17 \mu \mathrm{mol} / \mathrm{kg} \cdot \mathrm{min})$. When plasma FFA concentration was maintained with heparin, the plasma FFA oxidation rate remained constant at the basal level during the 4 and $20 \mathrm{mU} /$ $\mathrm{m}^{2} \cdot \mathrm{min}$ insulin clamp steps $(1.57 \pm 0.18$ and $1.61 \pm 0.18 \mu \mathrm{mol} /$ $\mathrm{kg} \cdot \mathrm{min}$, respectively; both $P<0.01$ vs. control study).

Nonoxidative FFA metabolism. The basal rate of nonoxidative FFA metabolism was similar in control and heparin experiments $(4.40 \pm 0.57$ vs. $4.96 \pm 0.46 \mu \mathrm{mol} / \mathrm{kg} \cdot \mathrm{min})$ (Fig. 4). During the 4 and $20 \mathrm{mU} / \mathrm{m}^{2} \cdot \mathrm{min}$ insulin clamp steps of the control study the basal rate of nonoxidative FFA metabolism declined by 51 and $62 \%$, respectively. When the plasma FFA concentration was maintained at the fasting level with heparin, the rate of nonoxidative FFA metabolism declined slightly, although not significantly from baseline and remained greater than during the control experiment $(P<0.01)$.

During both control and heparin studies plasma FFA concentration was strongly correlated with the rate of plasma FFA oxidation $(r=0.71 ; P<0.001 ; n=54)$ (Fig. 5), with the rate of nonoxidative FFA disposal $(r=0.84 ; P<0.001)$, and weakly with the rate of net lipid oxidation $(r=0.31 ; P<0.02)$.

\section{Glucose metabolism}

Hepatic glucose production (HGP). The basal rate of HGP was similar during the control and heparin studies $(2.0 \pm 0.13$ and $1.90 \pm 0.08 \mathrm{mg} / \mathrm{kg} \cdot \mathrm{min}$ ) (Fig. 6). During low-dose insulin infusion, HGP was reduced by $50 \%$ in control and heparin experiments (to $1.03 \pm 0.13$ and $1.19 \pm 0.18 \mathrm{mg} / \mathrm{kg} \cdot \mathrm{min}$, respectively). During the $20 \mathrm{mU} / \mathrm{m}^{2} \cdot \mathrm{min}$ insulin infusion, HGP was completely suppressed in both experiments.

Total glucose disposal. In the basal state the rate of glucose disposal equals the rate of glucose appearance (HGP) and was similar in control and heparin studies (Fig. 6). There was no significant enhancement of glucose disposal during the $4 \mathrm{mU} /$ $\mathrm{m}^{2} \cdot \mathrm{min}$ insulin infusion in either the control or heparin stud-

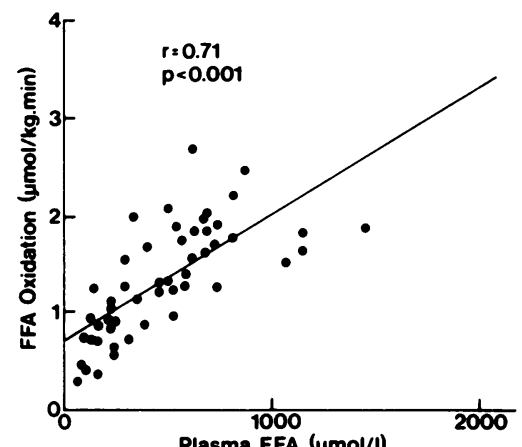

Figure 5. C rrelation between the plasma FFA concentration and the rate of plasma FFA oxidation in the basal state and during the 4 and $20 \mathrm{mU} / \mathrm{m}^{2} \cdot \mathrm{min}$ insulin clamp steps. 

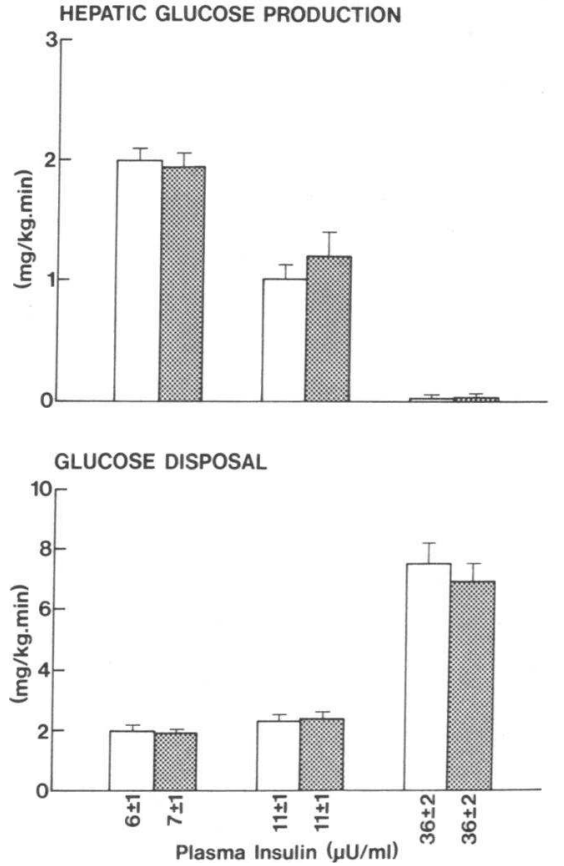

Figure 6. The rates of hepatic glucose production (top) and glucose disposal (bottom) in the basal state and during a two-step euglycemic insulin clamp (insulin infusion rates of 4 and $20 \mathrm{mU} / \mathrm{m}^{2} \cdot \mathrm{min}$ ) performed with saline (open bars) and with heparin (shaded bars). Values represent mean $\pm \operatorname{SEM}(n=9)$.

ies $(2.34 \pm 0.21$ vs. $2.39 \pm 0.24 \mathrm{mg} / \mathrm{kg} \cdot \mathrm{min})$. During the $20 \mathrm{mU} /$ $\mathrm{m}^{2} \cdot \mathrm{min}$ insulin clamp step, the rate of glucose disposal rose similarly in the control $(7.52 \pm 0.72 \mathrm{mg} / \mathrm{kg} \cdot \mathrm{min})$ and heparin $(6.98 \pm 0.60)$ studies.

Glucose oxidation. The respiratory quotients (RQs) in the basal state and during the +4 and $+20 \mathrm{mU} / \mathrm{m}^{2} \cdot \mathrm{min}$ insulin clamps were during the control study $0.82 \pm 0.01,0.83 \pm 0.01$, and $0.95 \pm 0.01$, respectively, and during the heparin study $0.83 \pm 0.01,0.81 \pm 0.01$, and $0.90 \pm 0.02$, respectively.

The basal rate of glucose oxidation was similar in control and heparin experiments $(1.52 \pm 0.15$ vs. $1.60 \pm 0.15 \mathrm{mg} /$ $\mathrm{kg} \cdot \min ; P>0.1$ ) (Fig. 7). During low-dose insulin infusion, there was no significant change in the rate of glucose oxidation in the control study $(1.55 \pm 0.15 \mathrm{mg} / \mathrm{kg} \cdot \mathrm{min})$, whereas there was a slight reduction during the heparin study $(1.19 \pm 0.20 \mathrm{mg} /$ $\mathrm{kg} \cdot \min ; P<0.05$ when comparing the change from basal between the two experiments). During the $20 \mathrm{mU} / \mathrm{m}^{2} \cdot \mathrm{min}$ insulin infusion, the rate of glucose oxidation was significantly reduced during the heparin vs. control study $(2.80 \pm 0.35$ vs. $3.71 \pm 0.24 \mathrm{mg} / \mathrm{kg} \cdot \min ; P<0.05$ ).

Nonoxidative glucose metabolism. The basal rate of nonoxidative glucose metabolism was similar in the two experiments $(0.48 \pm 0.12$ vs. $0.32 \pm 0.14 \mathrm{mg} / \mathrm{kg} \cdot \min )$ (Fig. 7$)$. There was no significant change in the rate of nonoxidative glucose metabolism during the low-dose insulin infusion in the control study $(0.79 \pm 0.22 \mathrm{mg} / \mathrm{kg} \cdot \mathrm{min})$, whereas there was an increase in the heparin study $(1.19 \pm 0.36 ; P<0.05)$. Although the rate of nonoxidative glucose disposal was enhanced during the $20 \mathrm{mU} /$ $\mathrm{m}^{2} \cdot \min$ insulin infusion in both the control and the heparin studies, there was no significant difference between the control and the heparin study $(3.81 \pm 0.66$ vs. $4.18 \pm 0.65 \mathrm{mg} / \mathrm{kg} \cdot \mathrm{min})$.
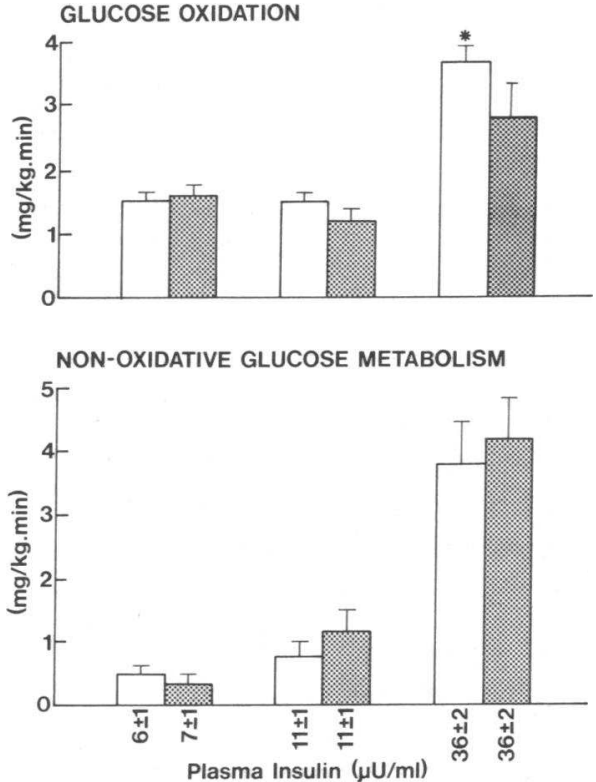

Figure 7. The rates of glucose oxidation (top) and nonoxidative glucose metabolism (bottom) in the basal state and during a two-step euglycemic insulin clamp (insulin infusion rates of 4 and 20 $\mathrm{mU} / \mathrm{m}^{2} \cdot \mathrm{min}$ ) performed with saline (open bars) and with heparin (shaded bars). Values represent mean $\pm \operatorname{SEM}(n=9)$. ${ }^{*} P<0.05$, significance of difference from the heparin experiment.

\section{Discussion}

In the present study we have examined the independent effects of insulin and FFA on total lipid oxidation, measured by indirect calorimetry, and plasma FFA oxidation, measured by ${ }^{14} \mathrm{C}$ palmitate. When insulin was infused to create physiologic increments in the plasma insulin concentration $(36 \pm 2 \mu \mathrm{U} / \mathrm{ml})$, both net lipid oxidation and plasma FFA oxidation declined in parallel. However, because the plasma FFA concentration also declined during the infusion of insulin, it was not possible to define whether the decline in plasma FFA/net lipid oxidation was due to a direct inhibitory effect of insulin or to a decrease in substrate delivery. To distinguish between these two possibilities, the plasma FFA concentration was "clamped" at the basal level by an infusion of heparin to activate lipoprotein lipase. Under these conditions insulin failed to inhibit plasma FFA oxidation but decreased net lipid oxidation by $>60 \%$. These results point at the existence of two distinct lipid pools which share the same oxidative pathway but whose input into this oxidative pathway is differentially regulated by insulin and plasma FFA supply. Oxidation of ${ }^{14} \mathrm{C}$-palmitate primarily reflects the circulating plasma FFA pool $(4,5,19)$ and is unaffected by insulin. In contrast, net lipid oxidation reflects both circulating plasma FFA as well as a large intracellular FFA pool, whose oxidation is sensitive to physiologic changes in the plasma insulin concentration.

In the basal state plasma FFA oxidation accounted for only $40-50 \%$ of net lipid oxidation. Our results indicate that the remaining $50-60 \%$ is derived from oxidation of intracellular lipids, which are not in equilibrium with the plasma FFA pool and therefore are not traced by the ${ }^{14} \mathrm{C}$-palmitate. Similar data have been reported by Issekutz et al. (5) in dogs. Dagenais et al. (4), using the forearm balance technique, also have provided 
evidence that intracellular oxidation of triglycerides and, possibly phospholipids, make a substantial contribution to total lipid oxidation in man. Similar results have been reported by Robin et al. (19) in nutritionally depleted patients who were suffering from acute infection or injury.

Consistent with the concept of a large intracellular lipid pool, Eaton et al. have shown that the plasma FFA pool exchanges with a 100 larger tissue pool, the bulk of which resides within the liver and muscle (20). Further support for this view has been provided by George and Naik, who demonstrated abundant lipid deposits in resting muscle (21). Hydrolysis of these intramuscular triglycerides/phospholipid stores with their subsequent intramuscular oxidation, or hydrolysis of lipoproteins in the capillary bed with immediate oxidation by adjacent muscle tissues, could explain the large discrepancy between total lipid oxidation and plasma FFA oxidation (22).

From the present results it can be concluded that physiologic increments in the plasma insulin concentration do not have a direct effect on the oxidation of circulating FFA. The plasma FFA concentration appears to be the main determinant of its own rate of oxidation. Several observations support this conclusion. First, inhibition of lipolysis by physiologic hyperinsulinemia causes a concomitant decline in the plasma FFA oxidation rate, which closely parallels the decline in plasma FFA concentration. Second, when the plasma FFA concentration was maintained constant by an infusion of heparin, the rate of plasma FFA oxidation was uninfluenced by insulin. Third, the plasma FFA concentration showed a strong positive correlation with the rate of plasma FFA oxidation and a similar correlation has been reported in dogs (10). Lastly, in vitro experiments have demonstrated that the rate of FFA oxidation increases in proportion to the increase in medium FFA concentration (23). Taken together, our data, as well as those of others, indicate that the rate of FFA oxidation is predominantly regulated by the plasma FFA concentration.

During the $20 \mathrm{mU} / \mathrm{m}^{2} \cdot \mathrm{min}$ insulin clamp step net lipid oxidation decreased even though the plasma FFA concentration remained unchanged. This could be due to one of two possibilities; insulin could suppress net lipid oxidation directly by inhibiting the oxidation of intracellular lipid stores, or inhibition of lipid oxidation could be secondary to stimulation of glucose oxidation by insulin (the Randle cycle). Our results suggest that insulin regulates net lipid oxidation via two distinct mechanisms. While its major action is to inhibit intracellular lipid oxidation (or to stimulate glucose oxidation), insulin also exerts a secondary effect on total lipid oxidation by modulating the plasma FFA concentration via its inhibitory action on lipolysis. Independent of changes in the plasma FFA concentration, insulin does not appear to affect plasma FFA oxidation.

Some comment concerning the discrepancy between net lipid oxidation measured by indirect calorimetry and plasma FFA oxidation measured by the tracer during the $+20 \mathrm{mU} /$ $\mathrm{m}^{2} \cdot \mathrm{min}$ is warranted. If lipogenesis from glucose is stimulated by insulin, this will be measured as an apparent decrease in lipid oxidation, even though no actual decrease in the oxidative flux of lipid carbons has occurred. This could result in underestimation of the true rate of lipid oxidation. The tracer-derived FFA oxidation measures the amount of lipid carbons which enter the oxidative pathway from the plasma pool. An increase in the recovery factor (which takes into account the incomplete recovery of labeled $\mathrm{CO}_{2}$ from the bicarbonate pool and was assumed to be 0.81 ) during hyperinsulinemia could result in overestimation of tracer-derived FFA oxidation. Recent evidence in dogs suggest that, in the fed state, the recovery factor may slightly increase, i.e., the retention of $\mathrm{CO}_{2}$ decreases (24). Although we did not measure recovery of ${ }^{14} \mathrm{CO}_{2}$ during hyperinsulinemic conditions, it is unlikely that this would signifcantly influence the results. An increase in the recovery factor from 0.81 to 0.90 would at most result in a $10 \%$ overestimation of the tracer-derived FFA oxidation rate. Still, during the +20 $\mathrm{mU} / \mathrm{m}^{2} \cdot \mathrm{min}$ insulin clamp with saline the rate of plasma FFA oxidation measured by the tracer is twice as high as the rate of lipid oxidation measured by indirect calorimetry. As some of the subjects presented with $R Q>1$ during this insulin infusion, we interpret the discrepancy between plasma FFA oxidation and net lipid oxidation as an indication that insulin increases significantly lipogenesis from glucose.

Our results also help to clarify the mechanisms which regulate the plasma FFA concentration in the basal and insulinstimulated states in healthy subjects. The plasma FFA concentration is determined by the rate of FFA appearance in the systemic circulation (lipolysis) and the rate of FFA disappearance (oxidation and reesterification). In the postabsorptive state plasma FFA oxidation accounted for $30 \%$ of total FFA turnover, while the remaining occurred via nonoxidative pathways, i.e., reesterification of FFA to triglycerides. The rate of nonoxidative FFA disposal can be estimated from the difference between the rate of total body FFA turnover and the rate of FFA oxidation $(6,18)$. Our data indicate that the major part (70\%) of FFA disposal during the basal state occurred via nonoxidative pathways. Insulin suppressed nonoxidative FFA disposal by 52 and $62 \%$, respectively, during the 4 and $20 \mathrm{mU} /$ $\mathrm{m}^{2} \cdot \mathrm{min}$ insulin clamp studies. However, nonoxidative FFA disposal still comprised $70 \%$ of total FFA turnover. Thus, in both the basal and insulin-stimulated conditions, reesterification represented the major route of plasma FFA disposal. During the insulin clamp studies performed with heparin the rate of nonoxidative FFA disposal failed to change from baseline, suggesting that insulin per se has no direct effect on FFA reesterification. The decline in nonoxidative FFA disposal observed when insulin was infused without heparin most likely is secondary to the decline in plasma FFA concentration. Consistent with this sequence, a strong positive correlation was observed between the rate of nonoxidative FFA disposal and the plasma FFA concentration. These findings are consistent with the concept that the plasma FFA concentration is a major determinant of nonoxidative FFA disposal or reesterification. Several other pieces of evidence support this concept. First, the rate of incorporation of FFA into triglycerides rises when the plasma FFA concentration is increased (20). Second, a positive correlation has been shown between the rate of FFA turnover and the appearance of FFA in triglycerides in dogs (25) and in man $(26,27)$. Third, glucose feeding in normal subjects leads to a decrease in plasma FFA concentration and a concomitant reduction in the rate of FFA reesterification (19).

The present results also provide some interesting information concerning the interaction between lipid/FFA and glucose metabolism. More than 20 years ago Randle and co-workers developed the concept of substrate competition, i.e., an increase in FFA oxidation leads to a decrease in glucose oxidation and vice versa (28). We previously have shown in normal subjects that the infusion of Intralipid during an insulin clamp resulting in a twofold increase in the basal plasma FFA concen- 
tration caused a significant reduction in the rates of oxidative and nonoxidative glucose disposal (29). In addition, the ability of hyperglycemia to inhibit basal HGP was impaired (29). In the present study, when the plasma FFA concentration was maintained constant at the basal level by heparin, the stimulatory effect of insulin on glucose oxidation was reduced, while nonoxidative glucose disposal remained unchanged. The results indicate, that providing more substrate for FFA oxidation under these conditions will only decrease the amount of glucose oxidized leaving the nonoxidative pathway unaffected. Furthermore, maintaining the FFA concentration unchanged at the basal level with heparin does not affect the inhibitory effect of insulin on HGP.

In summary, the data demonstrate that insulin has no direct effect on turnover and disposal of FFA when the plasma FFA concentration is maintained unchanged. They further suggest that oxidation of FFA from plasma and from intracellular lipid stores are differently regulated. Whereas the oxidation of plasma FFA is primarily determined by the plasma FFA concentration, the regulation of intracellular FFA oxidation is more complex and dependent upon both the plasma FFA and insulin concentration.

\section{Acknowledgments}

We thank Kathleen Zych, R.N., and Madelyn Mainiero, R.T., for their expert technical help and Dr. Rosa Hendler for kindly performing the insulin determinations. Dr. Leif Groop was the recipient of a Fogarty International Fellowship (FO5 TWO 3451) and Dr. Riccardo Bonadonna of a Fellowship from the Italian Ministry of Public Education. This research was supported in part by National Institutes of Health grant AM 24092 and CRC grant RR125.

\section{References}

1. Felber, J. P., E. Ferrannini, A. Golay, H. U. Meyer, D. Thiebaud, B. Curchod, E. Jequier, and R. A. DeFronzo. 1987. Role of lipid oxidation in pathogenesis of insulin resistance of obesity and type II diabetes. Diabetes. 36:1341-1350.

2. Thiebaud, D., E. Jacot, R. A. DeFronzo, E. Maeder, E. Jequier, and J. P. Felber. 1982. The effect of graded doses of insulin on total glucose uptake, glucose oxidation and glucose storage in man. Diabetes. 31:957-963.

3. Ferrannini, E. 1988. The theoretical basis of indirect calorimetry: a review. Metabolism. 37:287-301

4. Dagenais, G. R., R. G. Tancredi, and K. L. Zierler. 1976. Free fatty acid oxidation by forearm muscle at rest, and evidence for an intramuscular lipid pool in the human forearm. J. Clin. Invest. 58:421-431.

5. Issekutz, B., H. I. Miller, P. Paul, and K. Todahl. 1964. Source of fat oxidation in exercising dogs. Am. J. Physiol. 207:583-589.

6. Groop, L. C., R. C. Bonadonna, S. DelPrato, K. Ratheiser, K. Zyck, E. Ferrannini, and R. A. DeFronzo. 1989. Glucose and free fatty acid metabolism in non-insulin dependent diabetes mellitus: evidence for multiple sites of insulin resistance. J. Clin. Invest. 84:205-213.
7. Robin, A. P., M. Jeevandam, D. H. Elwyn, J. Askanazi, and J. M. Kinney. 1989. Measurement of fatty acid oxidation: validation of isotopic equilibrium extrapolation. Metabolism. 38:67-72.

8. DeFronzo, R. A., J. A. Tobin, and R. Andres. Glucose clamp technique: a method for quantifying insulin secretion and resistance. Am. J. Physiol. 237:E214-E223.

9. Fredrickson, D. S., and R. S. Gordon. 1958. The metabolism of albuminbound $\mathrm{C}^{14}$-labeled unesterified fatty acids in normal human subjects. J. Clin. Invest. 37:1504-1515.

10. Issekutz, B., P. Paul, H. I. Miller, and W. M. Bortz. Oxidation of plasma FFA in lean and obese humans. Metabolism. 17:62-72.

11. Altsuler, N. A., A. Barkai, A. Bjerknes, B. Gottlieb, and R. Steele. 1975. Glucose turnover values in the dog obtained with various species of labeled glucose. Am. J. Physiol. 225:1662-1667.

12. Hales, C. N., and P. J. Randle. Immunoassay of insulin with insulin antibody precipitate. Biochem. J. 88:137-146.

13. Hawk, P. D. 1947. Kjeldahl method. In Practical Physiological Chemistry. 12th ed. Blakiston, Toronto, Ont. 814-822.

14. Miles, J. R., J. Glassock, J. Aikens, J. Gerich, and M. Haymond. 1983. A microfluorometric method of free fatty acids in plasma. J. Lipid Res. 24:96-99.

15. Radziuk, J., K. H. Norwich, and M. Vranic. 1974. Measurements and validation of non-steady state turnover rates with application to the insulin and glucose system. Fed. Proc. 33:1855-1864.

16. Cobelli, C., A. Mari, and E. Ferrannini. 1987. Non-steady state: error analysis of Steele's model and development for glucose kinetics. Am. J. Physiol. 252:E679-E689.

17. Hagenfeldt, L., J. Wahren, B. Pernow, and L. Răf. 1972. Uptake of individual free fatty acids by skeletal muscle and liver in man. J. Clin. Invest. 51:23242330.

18. Waterhouse, C., N. Baker, and H. Rostami. 1969. Effect of glucose ingestion on the metabolism of free fatty acids in human subjects. J. Lipid Res. 10:487-494.

19. Robin, A. P., J. Nordenström, J. Askanazi, Y. A. Carpentier, D. H. Elwyn, and J. M. Kinney. 1984. Influence of parenteral carbohydrate on fat oxidation in surgical patients. Surgery (St. Louis). 95:608-618.

20. Eaton, R. P., M. Bierman, and D. Steinberg. 1969. Kinetic studies of plasma free fatty acid and triglyceride metabolism in man. J. Clin. Invest. 48:1560-1579.

21. George, J. C., and R. M. Naik. 1958. Relative distribution and chemical nature of the fuel store of the two types of fibres in the pectoralis major muscle of the pigeon. Nature (Lond.). 181:709-711.

22. Barter, P. J., and P. J. Nestel. 1969. Plasma free fatty acid transport during prolonged glucose consumption and its relationship to plasma triglyceride fatty acids in man. J. Lipid Res. 10:83-90.

23. Fritz, I. B. 1961. Factors influencing the rates of long chain fatty acid oxidation and synthesis in mammalian systems. Physiol. Rev. 41:52-129.

24. Hoerr, R. A., Y. Yong-Ming, D. A. Wagner, J. F. Burke, and V. R. Young. 1989. Recovery of ${ }^{13} \mathrm{C}$ in beath from $\mathrm{NaH}^{13} \mathrm{CO}_{3}$ infused by gut and vein: effect of feeding. Am. J. Physiol. 257:E426-E438.

25. Armstrong, D. T., R. Steele, N. A. Altzuler, A. Dunn, J. S. Bishop, and R. C. DeBodo. 1961. Regulation of plasma free fatty acid turnover. Am. J. Physiol. 201:9-15.

26. Miller, H. I., W. M. Bortz, and B. C. Durham. 1968. The rate of appearance of FFA in plasma triglyceride of normal and obese subjects. Metabolism. 17:515-521.

27. Nestel, J. 1967. Relationship between FFA flux and TGFA influx in plasma before and during infusion of insulin. Metabolism. 16:1123-1132.

28. Randle, P. J, P. B. Garland, and E. A. Newsholme. 1963. The glucose fatty acid cycle: its role in insulin sensitivity and the metabolic disturbances of diabetes mellitus. Lancet. i:785-789.

29. Ferrannini, E., E. J. Barrett, S. Bevilaqua, and R. A. DeFronzo. 1983. Effect of fatty acids on glucose production and utilization in man. J. Clin. Invest. 72:1737-1747. 